\title{
TRADUÇÃO COMO (I)MIGRAÇÃO: ADRIEN DELPECH, UM DOS PRIMEIROS TRADUTORES DE MACHADO DE ASSIS
}

\author{
TRANSLATION AS (IM)MIGRATION: ADRIEN DELPECH, \\ ONE OF THE FIRST TRANSLATORS OF MACHADO DE ASSIS
}

\author{
Marie-Hélène Catherine Torres \\ Universidade Federal de Santa Catarina/CNPq, Florianópolis, Santa Catarina \\ Universidade Federal do Ceará/CNPq, Fortaleza, Ceará, Brasil \\ marie.helene.torres@gmail.com
}

Resumo: O objetivo principal desse artigo é mostrar e dar visibilidade aos agentes intermediários da circulação das obras literárias, e, particularmente, a um tradutor esquecido pela história literária francesa e brasileira, Adrien Delpech. Pretendo, de um lado, teorizar sobre a problemática da tradução enquanto (i)migração, já que é sob o prisma e a partir dessa imagem e visão de mundo que Machado de Assis foi inicialmente traduzido em francês. De outro lado, faço um breve histórico sincrônico e diacrônico das primeiras traduções dos contos e romances do Machado no mundo para todas as línguas e culturas. E, finalmente, analiso o perfil de Adrien Delpech, um dos primeiros tradutores de Machado, responsável pela divulgação do autor não somente no sistema literário francês, mas também nos outros sistemas culturais-literários.

Palavras-chave: Tradutor de Machado de Assis; Adrien Delpech; Migração; Perfil do tradutor

Abstract: The main objective of this article is to show and give visibility to the intermediate agents of the circulation of literary works, and particularly to a translator forgotten by French and Brazilian literary history, Adrien Delpech. I intend, on the one hand, to theorize on the problematic of translation while (im)migrating, since it is under the prism and from this image and worldview that Machado de Assis was initially translated into French. On the other hand, I make a brief synchronic and diachronic history of the first translations of the stories and novels by Machado de Assis in the world for all languages and cultures. And, finally, I analyze the profile of Adrien Delpech, one of the first translators of Machado, responsible for the dissemination of the author not only in the French literary system, but also in other culturalliterary systems.

Keywordls: Machado de Assis translator; Adrien Delpech; Migration; Translator profile 
Vou mandar Roman Brésilien, de Adrien Delpech. Bem bom. São Paulo, 2 de setembro de 1904, Carta de Monteiro Lobato para Rangel.

(A barca de Gleyre, Volume 2)

O tema desse artigo está ligado à História da Tradução e dos Tradutores no Brasil e na França e visa ampliar as pesquisas que venho realizando desde 1997 sobre os escritores brasileiros traduzido na França, e particularmente Machado de Assis. A obra de Machado é uma das mais traduzidas da literatura brasileira nas línguas-culturas centrais, segundo a expressão de Casanova $(2002 ; 2020)$, e especialmente na França, com destaque para a recente tradução integral de Várias Histórias do Machado para o francês (Histoires diverses, traduzido por Saulo Neiva, publicado em 2015 e reeditado em 2017), o que demonstra a atualidade e o vigor do pensamento machadiano. Vou tentar mostrar aqui certa visibilidade dos agentes intermediários da circulação das obras literárias, e, particularmente, de um tradutor esquecido pela história literária francesa e brasileira, Adrien Delpech, o primeiro tradutor de Machado de Assis para o francês.

Proponho, em primeiro lugar, teorizar sobre a problemática da tradução enquanto (i)migração, já que é sob o prisma e a partir dessa imagem e visão de mundo que Machado de Assis foi inicialmente traduzido em francês. Em seguida, faço um breve histórico sincrônico e diacrônico das primeiras traduções dos contos e romances do Machado no mundo para todas as línguas e culturas, caracterizando a emigração. A terceira parte da apresentação, retomo a figura do Delpech enquanto escritor, principalmente a partir do estudo dos paratextos nas suas próprias traduções. E, finalmente, analiso e elaboro o perfil de Adrien Delpech enquanto imigrante, um dos primeiros tradutores de Machado no mundo, responsável pela divulgação do autor não somente no sistema literário francês, mas também nos outros sistemas culturais-literários

\section{O tradutor como (i)migrante, entre no mínimo, duas culturas}

A migração é o fenômeno humano ou animal que corresponde a um deslocamento maciço de um lugar para outro. Assim o animal deixa o lugar onde vive porque se tornou hostil, para chegar a outro lugar mais favorável à sua sobrevivência e, por vezes, à reprodução. Normalmente, no ano seguinte, ele deixa este segundo lugar e retorna ao seu ponto de partida. Este termo é muito mais usado quando se refere a animais e aos seus movimentos sazonais que afetam certas espécies, particularmente aves migratórias, certas borboletas, baleias, salmões etc. Em regra geral, concernentes aos deslocamentos humanos, fala-se de emigração ou imigração.

O tradutor pode ser apreendido como emigrante (e + migrante), ou seja, aquele que emigra, ou seja, que sai de um país para viver em outro ou como imigrante $(i+$ migrante $)$, aquele que imigra, ou seja, que entra num país para nele viver. Do ponto de vista do país/cultura em que o migrante entra para viver, este é visto ou chamado de imigrante. Apreendo, portanto, o tradutor como imigrante, considerando o tradutor indo e voltando de um lado e de outro da fronteira que separa ao mínimo duas culturas.

Para compreender a lógica do texto traduzido, é preciso voltar ao próprio trabalho tradutivo e, além disso, ao tradutor, como diz Antoine Berman (1995, p. 73). Assim, ao partir em busca do tradutor, ele faz claramente a pergunta: quem é o tradutor? Essa indagação tem uma finalidade diferente da dirigida a um autor (quem é o autor?), pois afirma que "a vida do 
tradutor não nos diz respeito, e a fortiori o seu estado de espírito". O que importa saber, segundo Berman, é se o tradutor é francês ou estrangeiro; se é somente tradutor ou se exerce outra profissão; se ele também for autor, se produziu obras; de qual(is) língua(s) traduz; se é bilíngüe; qual(is) gênero(s) de obras traduz; se escreveu sobre sua prática tradutiva; se traduziu com outros tradutores (tradução a "quatro mãos").

Anthony Pym tem uma visão completamente oposta à de Berman, pois vê os tradutores como pessoas de carne e osso, como seres humanos, e não como figuras do discurso que produziram uma tradução (PYM, 1998, p. 160). Ao contrário de Berman, Pym argumenta que alguns detalhes da vida particular, privada dos tradutores podem ser pertinentes para explicar o que foi feito na área da tradução. A hipótese de Pym é concerne à intercultura, que mostra que a nacionalidade do tradutor importa pouco, pois, segundo ele, o tradutor se situa na interseção das duas culturas, ou seja, no espaço intercultural. Ao contrário de Berman, que estabelece uma separação binária entre as duas culturas, ele não só afirma que os tradutores não pertencem a uma única cultura, como também que eles são a sua interseção (PYM, 1998, p. 177-182).

Levando-se em conta os critérios de Pym sobre a intercultura e o questionamento de Berman, pode-se estabelecer o perfil dos tradutores de uma cultura e literatura traduzida, considerando-se igualmente o discurso implícito dos paratextos (prefácio, notas do tradutor e outras introduções ou posfácios), assim como o dos metatextos (notas e glossários) e o dos outros textos escritos pelos tradutores. Todos esses documentos representam importantes fontes de informação e permitem analisar através do processo de tradução, as decisões e as estratégias de tradução tomadas pelos tradutores nas traduções. Isso me leva a apreender o tradutor como um (i)migrante, sempre entre duas ou mais culturas, na fronteira, no seuil ou passando a fronteira, passando o seuil, indo de um lado a outro desta ou deste, carregando sua bagagem, seja física ou intelectualmente falando.

\section{As primeiras traduções de romances e contos de Machado: a emigração}

Trato aqui da emigração das obras do Machado de Assis, ou em outras palavras, a exportação de suas obras para outras línguas-culturas: a tradução de suas obras para outras línguas-culturas. No seu artigo intitulado "Traducciones de Machado de Assis al español" (2012, p. 129-159), Pablo Cardellino faz um estudo minucioso das traduções existentes de Machado de Assis em espanhol. Segundo Cardellino, os primeiros contos traduzidos datam de 1911 (p. 149): Varias historias. Paris: Garnier Hermanos. [1911], traduzido por Rafael Mesa López, texto que encontrei na Biblioteca Numérica Francesa, Gallica em formato integral (http://gallica.bnf.fr/ark:/12148/bpt6k8595967.image).

Mas adiante, Cardellino afirma que Memórias Póstumas de Brás Cubas foi traduzido em 1902 por Julio Piquet. Informação também encontrada na resenha de Rosario Lázaro Igoa (2011) quando escreve que

a primeira tradução de Machado de Assis para qualquer língua foi publicada em Montevidéu em 1902. Tratava-se do romance Memórias póstumas de Brás Cubas, que apareceu no jornal La Razón, com tradução assinada pelo jornalista Julio Piquet. (IGOA, 2011).

Ora, trata-se de um livro que compila as traduções publicadas em folhetim no jornal uruguaio La Razón. Portanto, não é um projeto editorial original. Principalmente se considerarmos a definição de livro adotada em 1964 pela Conferência Geral da UNESCO 
(1974, p. 8) que é uma publicação não periódica impressa contendo no mínimo 49 páginas, capa não incluída. Mas, de qualquer forma, Piquet foi o primeiro a traduzir Memórias póstumas de Brás Cubas.

No tocante às traduções de romances e contos de Machado de Assis para a língua inglesa, me apoio em pesquisas realizadas por duas professoras pesquisadoras de Machado de Assis traduzido, Luana Ferreira de Freitas, da Universidade Federal do Ceará (UFC) e Cynthia Costa, da Universidade Federal de Uberlândia (UFU), principalmente na tese de doutorado da Prof a. Cynthia de 2016 intitulada Dom Casmurro em inglês Tradução e Recepção de um Clássico Brasileiro, e dados bibliográficos e históricos publicados em 2018 na revista Machado de Assis em linha por ambas. E finalmente, retomei minhas próprias pesquisas sobre a literatura francesa traduzida no Brasil em livros publicados na França e no Brasil entre 2004 e 2019, principalmente no que concerne ao Machado traduzido em francês.

Tanto Cardellino (2012), quanto Freitas e Costa (2018) ou ainda Torres (2004; 2011; 2014), bem como as pesquisas encontradas no site machadodeassis.org, trazem as referências das primeiras traduções dos contos e romances de Machado que estou sistematizando a seguir com o intuito de verificar quem são os primeiros tradutores de Machado de Assis no mundo:

Tabela 1 - Os primeiros tradutores de Machado de Assis no mundo

\begin{tabular}{|c|c|}
\hline \multirow{5}{*}{$\begin{array}{l}1^{0} \text { Tradutor de Memórias } \\
\text { Póstumas de Brás Cubas: } \\
\text { Julio Piquet (Uruguai, 1902) }\end{array}$} & $\begin{array}{l}\text { Memorias póstumas de Brás Cubas. Montevideo: } \\
\text { La Razón Montevideo: Imprenta de La Razón, } \\
\text { 1902. Trad. Julio Piquet. (Uruguai) }\end{array}$ \\
\hline & $\begin{array}{l}\text { Mémoires Posthumes de Braz Cubas. Paris : } \\
\text { Garnier frères, 1911. Trad. Adrien Delpech } \\
\text { (França) }\end{array}$ \\
\hline & $\begin{array}{l}\text { Memorias posthumas de Blas Cubas. Paris: } \\
\text { Garnier, 1911. Trad. Rafael Mesa López } \\
\text { (Espanha) }\end{array}$ \\
\hline & $\begin{array}{l}\text { Memorie postume di Braz Cubas : Milano : } \\
\text { Corbaccio, 1928. traduzione dal portoghese, } \\
\text { introduzione e note di Mario Da Silva (Itália) }\end{array}$ \\
\hline & $\begin{array}{l}\text { Memorie postume di Braz Cubas. Lanciano: } \\
\text { Carabba, 1929. Traduzione, introduzione, } \\
\text { biografiche e note del dr. Giuseppe Alpi (Itália) }\end{array}$ \\
\hline \multirow{3}{*}{$\begin{array}{l}1^{0} \text { Tradutor de Várias Histórias: } \\
\text { Adrien Delpech (França, 1910) }\end{array}$} & $\begin{array}{l}\text { Quelques contes. 1910. Trad. Adrien Delpech. } \\
\text { Paris: Garnier Frères }\end{array}$ \\
\hline & $\begin{array}{l}\text { Varias historias. Paris: Garnier Hermanos. } 1911 . \\
\text { Trad. Rafael Mesa López (Espanha) }\end{array}$ \\
\hline & $\begin{array}{l}\text { Brazilian Tales, 1921, Org. e trad. Isaac Goldberg } \\
\text { (“ contos de Várias Histórias: A cartomante, o } \\
\text { enfermeiro e Viver! (USA) }\end{array}$ \\
\hline \multirow{2}{*}{$\begin{array}{l}1^{\circ} \text { Tradutor de Dom Casmurro: } \\
\text { Rafael Mesa López (Espanha, } \\
\text { 1910) }\end{array}$} & $\begin{array}{l}\text { Don Casmurro. Paris: Garnier, 1910. Trad. } \\
\text { Rafael Mesa López (Espanha) }\end{array}$ \\
\hline & $\begin{array}{l}\text { Dom Casmurro. São Paulo: La Revista Coloniale, } \\
\text { 1914. Trad. Antonio Piccarolo (Itália) }\end{array}$ \\
\hline
\end{tabular}




\begin{tabular}{|l|l|}
\hline & $\begin{array}{l}\text { Don Casmurro. Roma: Ist. Cristoforo Colombo, } \\
\text { 1930. Traduzione di Giuseppe Alpi (Itália) }\end{array}$ \\
\hline $\begin{array}{l}\text { Francis de Miomandre nas publicações de 1936 } \\
\text { nstitut International de Coopération Intellectuelle } \\
\text { (França) }\end{array}$ \\
\hline $\begin{array}{l}\text { 10 Tradutor de Quincas Borba: } \\
\text { J. de Amber (Espanha, 1913) }\end{array}$ & $\begin{array}{l}\text { Quincas Borba. París: Garnier, 1913. Trad. J. de } \\
\text { Amber (Espanha) }\end{array}$ \\
\hline $\begin{array}{l}\text { La fortuna di Rubiano: (Quincas Borba). } \\
\text { Traduzione di Giuseppe Alpi. Milano: Corticelli, } \\
\text { 1934 (Itália) }\end{array}$ \\
\hline $\begin{array}{l}\text { Quincas Borba. Paris: Nagel, 1955, Col. Unesco } \\
\text { Euvres Représentatives. Trad. Alain de Acevedo } \\
\text { (França) }\end{array}$ \\
\hline
\end{tabular}

Fonte: Cardellino (2011), quanto Freitas e Costa (2018) ou ainda Torres (2004)

Conforme esta tabela dos primeiros tradutores de Machado de Assis no mundo, o primeiro tradutor de Memórias Póstumas de Brás Cubas é o uruguaio Julio Piquet que foi jornalista em La Razón de Montevideo, em El Censor Porteño e em La Nación e que publicou sua tradução em 1902 em Montevideo. As duas traduções que seguiram à tradução uruguaia foram publicadas no mesmo ano de 1911 pela mesma editora, a editora Garnier (que também era a editora de Machado no Rio de Janeiro). Uma é a tradução para o francês de Adrien Delpech, Mémoires Posthumes de Braz Cubas, e a outra, é a tradução para o espanhol de Rafael Mesa López, Memorias posthumas de Blas Cubas. As duas traduções seguintes são italianas, uma de 1928 de Mario Da Silva, Memorie postume di Braz Cubas, e outra em 1929 de Giuseppe Alpi, Memorie postume di Braz Cubas.

O primeiro tradutor de Várias Histórias é o tradutor-escritor francês Adrien Delpech que publicou sua tradução em 1910, Quelques contes, também pela editora Garnier. O ano seguinte, em 1911, o mesmo tradutor de Memórias Póstumas para o espanhol, Rafael Mesa López, publicará Varias historias pela mesma editora Garnier. O livro Várias Histórias não foi até hoje publicado integralmente em língua inglesa. Todos os dezesseis contos foram traduzidos de forma esparsa ao longo do século XX, e os três primeiros contos, "A cartomante", "O enfermeiro" e "Viver!" aparecem numa antologia estadunidense Brazilian Tales de 1921 traduzidos por Isaac Goldberg.

O primeiro tradutor de Dom Casmurro em 1910 é Rafael Mesa López (que traduziu Memórias Póstumas de Brás Cubas e Várias histórias) para o espanhol, seguido de duas traduções italianas, uma de Antonio Piccarolo publicada no Brasil em São Paulo pela Rivista Coloniale, em 1914 e outra de Giuseppe Alpi (o mesmo tradutor para o italiano de Memórias Póstumas) publicada em Roma em 1930, e finalmente, uma tradução francesa de Francis de Miomandre em 1936.

E finalmente, o primeiro tradutor de Quincas Borba é J. de Amber que traduziu o romance pela editora Garnier em 1913. As duas traduções seguintes foram publicadas décadas depois: uma italiana em 1934 por Giuseppe Alpi (o mesmo tradutor para o italiano de Memórias Póstumas de Brás Cubas e Dom Casmurro) com o título La fortuna di Rubiano: (Quincas Borba) e uma francesa por Alain de Acevedo em 1955. 
Em vista a esses dados, pode-se afirmar que a Editora francesa Garnier é a principal responsável e impulsora da imigração e emigração do Machado de Assis, no que Pascale Casanova chama de literaturas centrais.

\section{Delpech escritor sem fronteiras?}

Coloco nesse subtítulo um ponto de interrogação para avisar, de algum modo, o leitor de que o escritor tem um parti pris, tem sua visão de mundo, bem como faz jus ao que Toury chamou de inicial norm (1995). O escritor e/ou tradutor não é isente, nem imparcial ou invisível, mas sim tem preferências para um lado ou outro da fronteira ou até para o seuil onde se encontra a interseção entre as diversas culturas envolvidas.

O estudo do paratexto das traduções de Delpech podem ser uma fonte preciosa de informações sobre o conceito e projeto de tradução do tradutor, seja este consciente ou inconsciente, e sobre o processo de tradução. Conforme estudos anteriores que fiz (TORRES, 2011), podemos analisar o que chamo de aspecto "morfológico" e de discurso de acompanhamento. São as páginas de rosto, de falso título, as introduções, prefácios e outros posfácios que trazem detalhes sobre o estatuto das traduções, ou seja, sobre a maneira pela qual elas são percebidas conforme os elementos informativos que apresentam e onde, muitas vezes, a ideologia aparece de forma mais clara.

Mas, antes do estudo dos paratextos nas traduções do Delpech, preciso retomar a figura do Delpech escritor. De fato, ele publicou dois romances antes de publicar suas traduções:

\section{Linha do tempo - Adrien Delpech}

Escritor

1904: Roman brésilien, moeurs exotiques

1909: Petrópolis, pages exotiques

Tradutor

1910: traduz em francês Quelques contes, de Machado de Assis

1911: traduz em francês Mémoires posthumes de Brás Cubas, de Machado de Assis

1915-1934: Professor no Colégio Pedro II (Francês, Sociologia)

1929: Tornou-se membro da Associação de Ciências e Letras ${ }^{1}$ em 20 de janeiro de 1929

1930: $L$ 'Idole, seu $3^{\circ}$ romance

1942: Falece no RJ em 23/5/1942 - Sepultado no cemitério São João Batista.

A pesquisadora Ilana Heineberg da Universidade de Bordeaux Montaigne ao estudar o paratexto do primeiro romance de Delpech, Roman brésilien, afirma que os romances de Delpech "ressaltam o exótico e a cor local" (2016, p. 25). Heineberg resume a intriga da narrativa:

ao estrear com Roman brésilien, mœurs exotiques (1904), o adjetivo "exótico" aparece como decorrência do cenário brasileiro. A intriga amorosa envolve o médico Silvino e a jovem Fidélia, filhos de cafeicultores vizinhos do vale do rio Paraíba Fluminense que, por questões de poder local, tornam-se inimigos políticos, dificultando sua união. Inúmeras digressões permitem ao narrador descrever demoradamente a paisagem rural das fazendas de café e a paisagem urbana do rio de Janeiro, os jogos de poder

\footnotetext{
${ }^{1}$ Atualmente Academia Petropolitana de Letras.
} 
local no final do segundo império, as relações ora violentas, ora sensuais entre mestres e escravos às vésperas da abolição da escravidão, a ascensão do positivismo e, finalmente, a própria sanção da Lei Áurea. (HEINEBERG, 2016, p. 25).

Heineberg ressalta também que, numa nota prévia, Delpech evoca autores que escreveram sobre "países exóticos" limitando-se à "impressão do momento" (2016, p. 26). De fato, no final do século XIX, escritores como Pierre Loti, Gustav Aimard, Alfred Assolant despertaram o gosto pelo "romance exótico" que acompanhou o desenvolvimento das colônias francesas.

Ainda, no seu $2^{\circ}$ romance, Petrópolis, pages exotiques, Delpech faz uma dedicatória para Paul Auguste Marie Adam, um crítico literário e escritor francês que participou da homenagem ao Machado de Assis na "Fête de l'intellectualité brésilienne" (Festa da intelectualidade brasileira), na Sorbonne em abril de 1909. Eis a dedicatória:

\author{
A M. Paul Adam \\ En témoignage de haute admiration littéraire, et en souvenir de notre rencontre au \\ pays du soleil.
}

[Para M. Paul Adam

Com grande admiração literária e lembranças do nosso encontro no país do sol]

O exotismo do título se alastra na dedicatória. O Brasil é o país do sol, sol exotizado sob o olhar de Delpech. E isso se repete na introdução que faz ao romance e que apresento de forma bilíngue com tradução minha a seguir:

Introdução de Adrien Delpech ao seu romance Petrópolis, pages exotiques

\begin{tabular}{|c|c|}
\hline Introduction, Delpech (1909) & Introdução, Tradução de: Torres (2020) \\
\hline $\begin{array}{l}\text { Ce livre arrive à point, à un moment où } \\
\text { l'on s'intéresse vivement à tout ce qui se } \\
\text { passe dans l'Amérique du Sud, et où l'on } \\
\text { est en train de redécouvrir cette partie du } \\
\text { Nouveau Monde, au point de vue de ses } \\
\text { richesses exploitables et de ses efforts vers } \\
\text { la civilisation et le progrès. }\end{array}$ & $\begin{array}{l}\text { Este livro é oportuno, num momento em } \\
\text { que estamos muito interessados em tudo o } \\
\text { que está acontecendo na América do Sul, } \\
\text { e onde estamos redescobrindo essa parte } \\
\text { do Novo Mundo, com suas riquezas } \\
\text { exploráveis e seus esforços em prol à } \\
\text { civilização e ao progresso. }\end{array}$ \\
\hline $\begin{array}{l}\text { M. Adrien Delpech, qui a donné, il y a } \\
\text { quelques années, dans son "Roman } \\
\text { Brésilien » une si intéressante étude sur la } \\
\text { situation du Brésil au moment de } \\
\text { l'abolition de l'esclavage, complète la série } \\
\text { de ses observations, dans ce nouveau } \\
\text { roman, où il accompagne l'évolution du } \\
\text { même pays, depuis la proclamation de la } \\
\text { république jusqu'à ces derniers temps. } \\
\text { Pétropolis est une ville alpestre, située à } \\
\text { deux heures de Rio, dont elle est un } \\
\text { faubourg élégant. Le climat rappelle celui } \\
\text { de Nice. Le corps diplomatique y réside à }\end{array}$ & $\begin{array}{l}\text { O Sr. Adrien Delpech, que, alguns anos } \\
\text { atrás, apresentou no seu Roman Brésilien } \\
\text { (Romance Brasileiro) um estudo tão } \\
\text { interessante sobre a situação do Brasil na } \\
\text { época da abolição da escravidão, completa } \\
\text { as suas observações neste novo romance, } \\
\text { onde ele acompanha a evolução do mesmo } \\
\text { país, da proclamação da república até os } \\
\text { dias de hoje. } \\
\text { Petrópolis é uma cidade alpina, localizada } \\
\text { a duas horas do Rio, do qual é um } \\
\text { subúrbio elegante. O clima lembra o de } \\
\text { Nice. O corpo diplomático vive lá }\end{array}$ \\
\hline
\end{tabular}


demeure. Le livre de M. Adrien Delpech, en même temps qu'il s'attache à l'étude sociale du Brésil, peint aussi la société cosmopolite qui habite ce coin pittoresque des régions tropicales. Diplomates, gens d'affaires, snobs, sont pris sur le vif, et portraiturés d'un crayon ironique.

L'étude sociale se double d'une étude psychologique. «Comment la mentalité française d'un artiste, qui, à la maîtrise de son art, unit les complexités d'une àme de dilettante et de voluptueux, réagira-t-elle dans ce milieu différent et lointain ? » Le contraste de l'intellectualité des deux peuples est mis en évidence d'une façon très saillante par ce développement d'un caractère.

Ce n'est plus ici du roman d'aventures; c'est une étude documentaire, poussée très à fond par un écrivain qui, à l'habitude de voir et d'analyser, unit une grande connaissance de la société qu'il décrit. $\mathrm{M}$. Adrien Delpech est en effet professeur à l'École Normale de Rio.

Le livre est écrit dans un style souple et coulant qui, du dialogue rapide et brillant, s'élève à une grande hauteur dans la description, très riche en couleurs, et qui arrive à donner une sensation tactile et visuelle des paysages caractéristiques de la zone tropicale. permanentemente. O livro do Sr. Adrien Delpech, ao mesmo tempo em que se apega ao estudo social do Brasil, também retrata a sociedade cosmopolita que mora nesse canto pitoresco das regiões trópicais. Diplomatas, empresários, esnobes, são assim revelados e retratados com lápis irônico.

O estudo social se desdobra num estudo psicológico. "Como pode a mentalidade francesa de um artista que, dominando a sua arte, une as complexidades de uma alma de diletante e de voluptuosos, reagir neste ambiente diferente e distante?" O contraste da intelectualidade dos dois povos se destaca de maneira muito proeminente por este desenvolvimento de um caráter.

Não se trata mais do romance de aventura, mas sim de um estudo documentário, realizado com muita profundidade por um escritor que, acostumado a ver e analisar, une um grande conhecimento da sociedade que descreve. O Sr. Adrien Delpech é de fato professor na Escola Normal do Rio.

O livro, escrito num estilo flexível e fluente, a partir do diálogo rápido e brilhante, se eleva nas alturas na descrição, muito rico em cores, conseguindo transmitir uma sensação tátil e visual das paisagens características da área tropical.

\section{0 primeiro tradutor para o francês de Machado, Adrien Delpech o imigrante}

O perfil do tradutor permite entender os mecanismos das escolhas de tradução feitas por ele, bem como o processo de tradução. Conforme o Dicionário de Tradutores Literários no Brasil (DITRA), nascido na Bélgica em 1867, Adrien Delpech chega no Rio de Janeiro em 1896, e rapidamente se naturaliza brasileiro. No Rio de Janeiro, se casa com Clotilde Waguelin, de origem franco-suíça, com quem teve cinco filhos. Foi professor de diversos estabelecimentos renomados do Rio, incluindo o Colégio Pedro II. Foi o primeiro professor de Sociologia do Colégio Pedro II e, antes de se tornar catedrático interino, Delpech foi professor substituto de francês escolhido pela Congregação. Regeu interinamente a cadeira de Francês do Internato de 1915 a 1917 além de ter sido colaborador em vários periódicos brasileiros como $O$ País, $O$ Jornal e o Jornal do Comércio. 
Na literatura, sua trajetória é reconhecida internacionalmente, pois, além do ensino de francês e sociologia, Delpech era próximo de autores como Raimundo Corrêa, Alberto de Oliveira e Olavo Bilac. Ele mesmo era escritor e publicou romances no Brasil, sobre o Brasil, em língua francesa. Ele foi também o primeiro tradutor de Machado de Assis para a língua francesa, como falamos anteriormente. A sua tradução de Quelques contes (Várias histórias) foi publicado em 1910, um ano após a festa da Latinidade, na Sorbonne, evento que homenageou a intelectualidade brasileira e Machado de Assis, falecido em 1908. No dia 20 de janeiro de 1929, Delpech é recebido como novo membro da Associação de Ciências e Letras, fundada em 1922 e que, futuramente, se tornaria a Academia Petropolitana de Letras. Sob os auspícios de Alcindo Azevedo Sodré, médico, escritor e político, e também redator do Jornal de Petrópolis, Delpech é saudado em sua cerimônia de recepção como "uma das mais brilhantes mentalidades que se encontram em Petrópolis". Faleceu no Rio de Janeiro no dia 23 de maio de 1942 onde foi sepultado no cemitério São João Batista.

Além e junto ao perfil do tradutor, é importante se debruçar sobre a questão do estudo dos paratextos nas traduções do Delpech, pois permitem "especular" de forma crítica sobre as estratégias e escolhas feitas no processo de tradução. Para o estudioso em Estudos da Tradução, há claramente dois tipos de paratextos nas obras traduzida: de um lado, os paratextos préexistentes na obra "original" (original que coloco entre aspas, pois considero a obra traduzida como um original, um outro original) que serão ou não traduzidos pelo tradutor e, do outro lado, os paratextos de autoria do tradutor, editor e outro prefaciador. Refiro-me aqui do último tipo de paratextos.

Das duas traduções que Delpech fez do Machado, a única que apresenta um paratexto do tradutor é Quelques Contes. Em seu prefácio, Delpech revela suas ideias sobre a atividade tradutória da obra e afirma, por exemplo, ao citar Anatole France que

Il y a de belles traductions, peut-être, il n'y en a pas de fidèles... Chaque lecteur substitue ses visions aux nôtres... Que devient l'idée, la belle idée sous ces méchants hiéroglyphes à la fois communs et bizarres ? Qu'est-ce qu'il en fait, le lecteur, de ma page d'écriture? Une suite de faux sens, de contresens et de non-sens.

[Há belas traduções, talvez; traduções fiéis não há... Cada leitor substitui suas visões às nossas... $\mathrm{O}$ que acontece com a ideia, a bela ideia sob estes hieróglifos malignos, ao mesmo tempo comuns e estranhos? O que é que o leitor faz da minha página de escrita? Uma série de falsos sentidos, contrassensos e de non sense.]

Delpech deplora a sua visibilidade enquanto tradutor e sua infidelidade, conceitos largamente difundidos no início do século XX e que perduram, infelizmente até hoje no século XXI em algumas línguas-culturas:

J'ai traduit Machado de Assis, c'est-à-dire que j'ai superposé à sa mentalité une autre mentalité bienveillante et aussi harmonique que possible avec la sienne. Et c'est le rôle fatal de tout traducteur, essayât-il de faire une traduction juxtalinéaire, en créant même des néologismes à tout bout de champ, comme Chateaubriand dans sa traduction du Paradis perdu. À travers Milton, on retrouve encore Chateaubriand.

[Traduzi Machado de Assis, ou seja, sobrepus a sua mentalidade outra mentalidade benevolente e a mais harmoniosa possível com a sua própria. E esse é o papel fatal de qualquer tradutor, mesmo que tentasse fazer uma tradução justalinear, criando neologismos sem parar, como Chateaubriand na sua tradução do Paraíso perdido. Através de Milton, ainda encontramos Chateaubriand.] 
Quando o prefácio que introduz o texto é assinado pelo tradutor, como é o caso do prefácio do Delpech, este é raramente seguido de notas do tradutor onde podem ser mencionadas as escolhas de tradução. Como apreendo o texto traduzido como um outro texto, escrito em outra língua-cultura para outros leitores para os quais o texto não foi escrito na origem, no tempo e no espaço, considero que o tradutor é um autor, autor do texto que traduziu com marcas indentitárias do texto primeiro.

Portanto, os prefácios escritos pelos tradutores são textos autorais (tornando o prefaciador autor do texto que segue) e não alógrafos (onde o prefaciado não seria o autor do texto que segue). Delpech, escritor-tradutor, que intenciona mostrar certo exotismo e visão colonial francesa, reflete sobre sua tarefa de tradução a partir da sua ética do traduzir/transcrever o processo de negociação identitário que acaba criando uma nova forma de escrita: o encontro das línguas e culturas. Delpech aborda, assim, questões de tradução sob a perspectiva do imigrante, do discurso híbrido e das transfronteiras da tradução, mostrando uma nova relação entre fatos literários e o mundo.

\section{Referências}

BERMAN, A. Pour une critique des traductions: John Donne, Paris, Éditions Gallimard, 1995.

BHABHA, H. O local da cultura. Tradução de Myriam Ávila. Belo Horizonte: Editora UFMG, 2013.

CARDELlinO, P. Traducciones de Machado de Assis al español. In: Machado de Assis: tradutor e traduzido. GUERINI, A.; FREITAS, L. F.; COSTA, W. C. (orgs.). Tubarão: Ed. Copiart, 2012.

CASANOVA, P. A República Mundial das Letras. Tradução de Marina Appenzeller. São Paulo: Estação Liberdade, 2002.

CASANOVA, P. A língua mundial. Tradução e dominação. Tradução de Marie Helene Catherine Torres. Florianópolis/Brasília: EDUFSC/Ed. UNB, 2021.

COSTA, C. B. Dom Casmurro em inglês: tradução e recepção de um clássico brasileiro. 2016. Tese (Doutorado) - Universidade Federal de Santa Catarina, Centro de Comunicação e Expressão, Programa de Pós-Graduação em Estudos da Tradução, Florianópolis, 2016. Disponível em: https://repositorio.ufsc.br/handle/123456789/168032. Acesso em 08 abr. 2020.

COSTA, C. B.; FREITAS, L. F. Resenha de Histoires Diverses, de Saulo Neiva. Machado de Assis em linha, v. 11 n. 25, 2018.

GUERINI, A.; FREITAS, L. F.; COSTA, W. C. (orgs.). Machado de Assis: tradutor e traduzido. Tubarão: Ed. Copiart, 2012. 
HEINEBER, I. Um Brasil para francês ler: das traduções de o Guarany e de Innocencia ao exotismo dos romances de Adrien Delpech. In: ABREU, M. Romances em movimento: a circulação transatlântica dos impressos (1789-1914). São Paulo: Unicamp, 2016, p. 189-222.

IGOA, R. L. CAMPOS, Haroldo de. Galaxias/Galáxias. Tradução ao espanhol e notas de Reynaldo Jiménez. Prólogo de Roberto Echavarren. Montevidéu: La Flauta Mágica, 2010. Revista Gragoatá, n. 31, 2011.

PYM, A. Method in Translation History. Manchester, St Jerome Press, 1998.

SIMON, S. La culture transnationale en question : visées de la traduction chez Homi Bhabha et Gayatri Spivak. Études françaises, v. 31, n. 3, p. 43-57, 1995.

STAUT, L. M. V. O estilo machadiano e o tradutor. Revista Alfa, n. 36, p. 111-117, 1992.

TORRES, M. H. C. Variations sur l'étranger dans les lettres: cent ans de traductions françaises des lettres brésiliennes. Lille: Artois Presses Université, 2004.

TORRES, M. H. C. Traduzir o Brasil literário: Paratexto e discurso de acompanhamento. Tubarão: Copiart, PGET/UFSC, v. 1, 2011.

TORRES, M. H. C. Traduzir o Brasil literário: História e Crítica. Tubarão: Copiart, PGET/UFSC, v. 2, 2014.

TOURY, G. Descriptive Translation Studies and Beyond. Amsterdam and Philadelphia: Benjamins, 1995.

\section{Fontes consultadas:}

ACADEMIA BRASILEIRA DE LETRAS. Machado de Assis. Disponível em: https://www.machadodeassis.org.br/abl_minisites/cgi/cgilua.exe/sys/startd466.html?UserActi veTemplate $=$ machadodeassis \&sid=89\&from_info_index $=1 \&$ tpl=printerview_default. Acesso em 08 abr. 2020.

ADRIEN DELPECH. In: Dicionário de Tradutores Literários do Brasil (DITRA). UFSC. Disponível em: http://www.dicionariodetradutores.ufsc.br/pt/AdrienDelpech.htm. Acesso em 08 abr. 2020.

AZUA, C. R. Julio Piquet, Escritor. Letras Nacionales, 1995. Autores del Uruguay. Disponível em:

http://www.autoresdeluruguay.uy/biblioteca/Carlos_Real_De_Azua/lib/exe/fetch.php?media= real_-_julio_piquet_793-diciembre-09-1955.pdf. Acesso em 08 abr. 2020.

BLASIO, M. G. Catallogo delle monogafie. Disponível em:

http://bibliotecafilosofia.uniroma1.it/Fondilibrari/Gentile/cat/cat_compl_mon.pdf. Acesso em 08 abr. 2020. 
UNESCO. Pour le livre. UNESCO, 1974: Disponível em:

https://unesdoc.unesco.org/ark:/48223/pf0000137835. Acesso em 08 abr. 2020.

SOARES, J. C. A Identidade Profissional dos Primeiros Professores de Sociologia do

Colégio Pedro II. Anais do $3^{\circ}$ Encontro Estadual de Ensino de Sociologia. Rio de Janeiro:

UFRJ, 2012. Disponível em: http://www.labes.fe.ufrj.br/Eventos/3ENSOC/PDF/GT1.1.1.pdf Acesso em 08 abr. 2020.

VASCONCELLOS, F. J. R. Adrien Delpech. Instituto Historico de Petrópolis. Disponível em: http://ihp.org.br/?p=415. Acesso em 08 abr. 2020.

Recebido em: 25 de junho de 2020 Aceito em: 13 de outubro de 2020

Publicado em dezembro de 2020 